\title{
Yeni Kamusal Alan Oluşturma Potansiyeli Bakımından Yurttaş Gazeteciliği
}

DOI: $10.26466 /$ opus. 893723

\author{
Nihal Paşalı Taşoğlu* - Sema Çağlayan** \\ * Doç. Dr., Kocaeli Üniversitesi, İletişim Fakültesi, Kocaeli/Türkiye \\ E-Posta: nihal.pasali@kocaeli.edu.tr \\ ORCID: 0000-0003-2985-5638 \\ ** Doktora Öğrencisi, Kocaeli Üniversitesi, Sosyal Bilimler Enstitüsü, Kocaeli/Türkiye \\ E-Posta: semacaglyan@gmail.com \\ ORCID: $0000-0002-5715-8744$
}

\section{Öz}

İletişim ve bilgi teknolojilerinin gelişimi ile birlikte toplumlar "ă̆ toplumuna" doğru bir geçiş yaşamakta ve bireyler teknolojiyi kullanarak tüketici konumundan üretici konumuna nasıl geçeceklerini keşfetmektedirler. Ve yine bireyler, çeşitli iletişim ağlarıyla etkileşimde olan toplumda kolektif algı oluşturma, farklı fikirler etrafinda birleşme ve katılımo kültürü yükseltme üzerine pratikler edinmektedirler. Bu gelişmeler, bireylerin devletten ve piyasa ekonomisinden bağımsız olarak görece daha özgür davranabilecekleri yeni kamusal alan arayışlarını ve yurttaş gazeteciliği kavramını akıllara getirmektedir. Çalışmanın amacı, yurttaş gazeteciliği kavramının taşıdığı özellikler bakımından yeni bir kamusal alan olarak konumlandırılıp konumlandırılamayacağın tartışmaktır. Bu bağlamda öncelikle kamusal alan yaklaşımları ve yurttaş gazeteciliği kavramı üzerinde durulmuş, devaminda yurttaş gazeteciliğinin kamusal alan niteliği, medya, internet ve sosyal ă̆lar dahilinde şekillenen yeni kamusal alan yaklaşımlar bağlamında ele alınarak tartışılmıştır. Çalışmada kullanılan yöntem literatür taramasıdır. Sonuç olarak yurttaş gazeteciliğinin sahip olduğu özellikler itibari ile yeni kamusal alan niteliğini sağlaması, ekonomipolitiğinin bağımsız olmasına; baskl, tekelleşme ve sansürden uzak olmasına; katıllmoılıkta eşitliğin sağlamasına ve tüm görü̧slerin eşit şekilde temsil edilebilmesine bağglı olduğu çıkarımına varılmıştır.

Anahtar Kelimeler: Yurttaş Gazeteciliği, Kamusal Alan, Yeni Kamusal Alan, Yeni Medya, Internet. 


\title{
Citizen Journalism in Terms of Potential for Creating a New Public Sphere
}

\begin{abstract}
With the development of communication and information technologies, societies are experiencing a transition towards a "network society" and individuals are discovering how to move from the "consumer status" to the "producer status"by using technology. Individuals acquire practices on creating collective perceptions, uniting around different ideas, and increasing participatory culture in the society that interacts with various communication networks. These improvements bring to mind the concept of citizen journalism and the search for new public spheres in which individuals can act relatively more free independent from the state and the market economy. The aim of the study is to discuss whether the concept of citizen journalism can be positioned as a new public space in terms of its characteristics. In this context, primarily, public sphere approaches and the concept of citizen journalism were emphasized, and then the public sphere nature of citizen journalism was discussed in the context of new public sphere approaches shaped within media, internet and social networks. The method used in this study is the literature review. As a result, it is concluded that providing the new public sphere in terms of the characterization of citizen journalism depends on its independence from economic-political status, being away from oppression, monopolization and censorship, and also it depends on providing equal participation and equal representation of all views.
\end{abstract}

Key Words: Citizen Journalism, Public Sphere, New Public Sphere, Media, Internet. 


\section{Giriş}

Teknolojinin gelişmesi ve teknolojik yeniliklerin, yaşamın çoğu alanında hayatı kolaylaştıııcı bir etken olması, onun kullanım alanını ciddi oranda genişletmiştir. Bilgisayar, cep telefonu, dijital kameralar gibi gereçlere herkes tarafından kolay ulaşılabilmesi ve bu cihazların sunduğu imkânlar, iletişim evrenini de şekillendirmiş ve bugün dünyanın yeni bir platformda etkileşimini sürdürmesine olanak tanımıştır. Küresel anlamda İnternet kullanımının da bu gelişmeye paralel şekilde artması, iş yapış şekillerini, ticareti, pazarlamayı, iletişimi ve daha pek çok alanı dönüştürmüş ve etkileşimin artmasını sağlayacak yeni ortamlar yaratmıştır.

A $\breve{g}$ toplumunun yükselişi, bilginin gücü ve kontrolünün jeo-politiği için derin gönderimler taşıyan yöntemlerle, gezegeni yeniden birbirine bağlamaktadır (Allan ve Thorsen, 2019, s.20). Teknolojinin ve internetin bu yöndeki gelişimi kişiler arasındaki iletişimi de etkilemiş; bireyler çeşitli konularda fikirlerini ifade edebilecekleri yeni medya araçlarıly tanışmışlardır. Web ortamları, bloglar, sosyal medya araçları, foto paylaşım siteleri gibi ağlarda kişiler gerçek ya da gizli kimlikleriyle paylaşım yapabilmekte, görüşlerini ifade edebilmekte, sosyalleşebilmekte ve örgütlenebilmektedirler. Bu yönüyle yeni medya ortamları, kamusal alan kavramını gündeme getirmektedir.

İnternet ortamının sunduğu, görece özgür ortamlarda oluşturulmuş bloglar ve sosyal ağlarda bireyler, ana akım medyada yeterince dile getirilmeyen ya da haber değeri taşımadığı düşünülen sorunlara değinebilmekte; anayasal haklar, çevre hakları, çalışan hakları, yoksulluk gibi konuları gündeme getirerek tartışabilmektedir. Ayrıca toplumun geneli ile birlikte daha küçük gruplara ait risklerin görülebilir olmasını sağlayabilmektedirler. Forumlar açabilmekte, tartışmalar başlatabilmekte ve yeni teknolojilerin sağladığı hız, etkileşimsellik ve mekândan bağımsız olma özelliği sayesinde geniş kitlelere erişebilmekte ve seslerini duyurabilmektedirler. Muhabirlerin ilk gerçekleştiği anda orada bulunmasının pek mümkün olmadığı doğal afetler ve kriz anları gibi durumlarda da bireyler tanıklık ettikleri olayları teknolojik imkânlar ve yeni medya kanalları ile anında diğer insanlarla paylaşabilmekte ve bir gazeteci rolüne bürünebilmektedir. Tüm bu pratikler, bütün dünyada uygulama alanını 
genişletmeye başlayan yurttaş gazeteciliği kavramının şekillenmesinde aktif rol oynamaktadır.

Tüm dünyada, etkileşimde bulunma, fikirleri ortaya koyma, çeşitli konular hakkında tartışarak kanıya varma gibi potansiyelleri taşıyan kamusal alan kavramı da iletişim teknolojilerinin gelişmesi ve yaygın kullanımı ile yeni bir boyuta taşınmıştır. 18. yüzyılın kafelerindeki fiziki ortam, artık yerini siber mekâna bırakmaya başlamıştır. Yaşanan bu dönüşüm, yurttaş gazeteciliği olgusunun da bir kamusal alan olarak tartışılabilinirliğini gündeme getirmiştir.

Çalışmada ele alınan konu, yurttaş gazeteciliğinin konumlandırıldığı platformların kamusal alan niteliğinin sorgulanması ile birlikte, bugüne kadar deneyimlenmiş yurttaş gazeteciliği pratiklerinin ortak problemleri dile getirme, katılımcı kültür oluşturma, kendi gündemini yaratma, toplumun yararına düşünme gibi özelliklerinin kamusal alanın menfaatleriyle örtüşüp örtüşmediği; dolayısıyla kamusal alan niteliği taşıyıp taşıyamayacağıdır.

Kuramsal ve kavramsal yapı bakımından bu çalışmada öncelikle ağ ve iletişim teknolojileri ile yeni bir boyut kazanmış olan "yeni kamusal alan" kavramı ve yaklaşımlarına yer verilmiş; devamında "yurttaş gazeteciliği" kavramı açıklanmıştır. Son olarak yurttaş gazeteciliğinin yeni bir kamusal alan niteliği taşıyıp taşımadığı sorusuna yanıt aranacaktır. Çalışmada literatür taraması yöntemi kullanılacaktır.

\section{Kamusal Alan Kavramı}

Kamular, aynı gündem konuları veya meselelere dair sorun, kısıt ve ilgi dereceleri birbirine yakın olan insanlardan oluşan bir yapıdır (Grunig ve Repper, 2005, s.153). Dewey (1927) ve Blumer (1966)'a göre kamular, “onları etkileyecek boyutta sonuçlar doğuran sorunlar neticesinde gelişmektedir; sorun yaratmanın ötesinde kamular, mevcut sorunlar sonucunda doğmaktadırlar" (Grunig ve Repper, 2005, s.153). Dewey'e göre bir kamu, sadece paylaştığı ortak sorunları fark eden insanları ifade etmemektedir. Demokrasi, ortaya çıkan bu sorunların tartışılmasını ve anlaşılmasını gerektirmektedir. Kamu, potansiyel olarak mevcuttur ve 
gerçektir. Bu kamunun ortaya çıkması, siyaset, kültür, eğitim ve gazetecilik gibi kurumların işini daha iyi yapmasına bağlıdır (Uzun, 2006, s.637-638).

Sosyal bilimciler için kamu kavramı grup ile eşanlamlı olarak kullanılmaktadır. Kimi zaman az sayıda katılımciyla, kimi zaman da toplumun genelini ilgilendiren konular etrafında geniş katılımla meydana gelen kamular için karşılıklı etkileşim ve süreklilik, en önemli iki özelliktir (Atabek, 2002, s.224). Dewey (1972), kamuların etkilendikleri sorunları ayrıştırdıktan sonra, gündem grupları biçiminde örgütlenerek sorun yaratan ya da sorunların çözümüne yardım etmekle yükümlü olan örgütlere baskı yaptıklarını belirtmiştir. Bu perspektifte kamular, ortak sorunlar yaşayan bireylerin oluşturduğu birbirinden kopuk sistemler olarak doğmakta, zamanla kolektif davranış sergileyen örgütlü ve güçlü eylem gruplarına dönüşebilmektedirler (Grunig ve Repper, 2005, s.153). Sorunları gündemleştiren kamular, tipik olarak kitlesel medyayı kullanmaktadırlar. Bu yönde protestolar, yürüyüşler gibi eylemler düzenlemektedirler. Konu medyada daha çok yer aldıkça toplumun geniş kesimi konudan haberdar olmakta ve kamular, sıcak gündem kamularına dönüşmektedirler (Grunig ve Repper, 2005, s.164).

Kamuların ortak bir sorunsal çevresinde birleşmesi kamuoyu olgusunu doğurmaktadır. Kamuoyu, "toplumsal değerlerden ziyade, toplumu ilgilendiren sorunlar karşısında geliştirilen ortak kanı, düşünce ve tavırları" ifade etmektedir (Çelebi, 2004, s.264-265). Habermas kamuoyunun, yurttaşların oluşturduğu kamusal gövdenin devlet şeklinde örgütlenen egemen yapıya karşı, enformel ve seçim dönemlerinde formel olarak yürüttügü eleştiri yapma ve onu kontrol edebilme görevlerine işaret etmiştir (Habermas, 2004, s.95). İlkesel olarak kanaatler, kamuoyunun hammaddesini oluşturmaktadır. Habermas (1962)'a göre kolektif önyargılar, değerler ve kültürel varsayımlar içinde kurulan gündelik düşünce biçimleri, yani ortak duyunun ürünü olarak kanaatler, kamusal tartışma ve eleştirinin süzgecinden geçirilmektedir. Bu biçimiyle kamuoyu, kanaatleri işleyen eleştirel aklın ürünü olarak ortaya çıkmaktadır. Habermas, iyi işleyen politik bir kamusal alan olmadan meydana gelmiş kamuoyunu, "kamusal olmayan kanaat" şeklinde tanımlamıştır (Özbek, 2004a, s.42). Dolayısıyla kamusal alan, kamunun kanaatlerinin 
çoğulu temsil edecek düzeyde şekillenmesi ve işlerlik kazanabilmesi için gereken ortamı sağlayan bir yapıdır.

Kamusal alan, "modern toplumun temel bir özelliği olmakla birlikte; aynı zamanda, özgür, kendi kendini yöneten bir toplum olarak insanların fikirlerini özgürce ifade edebildiği, bireysel ya da ortak bir akılla oluşturdukları ortak görüşlerin ifade edildiği", "bütün vatandaşların erişim hakkı taşıdığı, kamu ile ilgili konuların tartışıldığı ve kamuoyunun şekillendiği bir alandır" (Taylor, 1992, s.221; Odabaş, 2018, s.2052). Bir toplumda mevcut olan kamusal alanın genişliğini ve sınırlarını düşünce, ifade, tartışma, bilgiye erişim, örgütlenme ve tanınma özgürlüklerinin ne kadar gelişmiş olduğu, birey ayırt etmeksizin herkesi kapsayıcılığı belirlemektedir (Özbek, 2004a, s.32). Kamusal alanda yer alan mesajlar ve tartışmalar, insanların hayatları ve insanlığın geleceğini etkileyen konularda verdikleri kararları etkilemektedir (Castells, 2008, s.89-90).

Kamusal alan kavramını geniş kapsamlı ele alarak tanımlayan sosyologların başında Habermas vardır. Habermas (2018) kamusallı̆̆ı, "eleştiri ve iletişim alanı" olarak değerlendirmiştir ve kamusal alanı "kamusal ilgi ya da ortak fayda konularını tartışmak için bir araya gelen kişilerden oluşan bir yapı" olarak tanımlamıştır. Siyasal anlamda kamusal alan, sivil toplum ile devlet arasında eleştirel kamusal tartışmaların kurumsal olarak sürdürüldügü bir yapıdır ve gelişmekte olan bir ekonominin kendine özgü koşulları içinde oluşmuştur. Giderek güçlenen burjuva, mevcut iktidar ya da devlet otoritesinin yurttaşlar tarafından eleştirel tartışma aracılığıyla denetlendiği bir kamusal alanın oluşmasına katkı sağlamıştır. Eğitimin niteliği, özel mülkiyete sahip olmayla kazanılmış olan özerklik ile birlikte bağımsızlık, eleştirel düşüncenin gelişmesine katkı sağlayan romanlar, kafelerdeki politik diyaloglar ve militan gazeteler, eleştirel siyasi tartışmalarla ilgili yurttaşların oluşturduğu bir kamusal alan yaratmıştır (Avc1, 2010, s.22).

Habermas (2018), kamusallığın alt yapısının, genişleyen ve yeni okur kitlesine hitap eden kitap üretiminin örgütlenme, dağıtım ve tüketim yapıları ile içeriği itibariyle değişim geçiren gazete ve basınla beraber değişime uğradığını belirtmektedir. Bu alt yapının zaman içindeki değişimin nedeninin elektronik kitle iletişim araçlarının yükselişi, reklamın kazandığı yeni ehemmiyet, eğlence ile bilgilenmenin gittikçe birbirinin içine akması, her alanda artan merkezileşme, liberal dernekçiliğin ve bir bakışta 
hâkim olunabilir yerel kamusallıkların çöküşü olduğunu ifade etmektedir. Habermas, medyanın, özel mülkiyet sahiplerinin kendi çıarları doğrultusunda kullandığı bir sosyal alana dönüştüğünü ve bu durumun devlet ile halk arasındaki uçurumu daha da artıran ve kamusal alanın çöküşüne zemin hazırlayan sebep olduğunu belirtir. Bunun sonucunda temsili kamusallıktaki temsili siyasi katılım, yerini seyirciliğe bırakmaktadır (Odabaş, 2018, s.2055).

Yirminci yüzyılın sonlarındaki refah devleti kitle demokrasisinin değişen koşulları altında, Habermas tarafından öne sürülen burjuva veya liberal kamusal alan modelinin artık uygulanabilir olmadığını belirten Fraser (1990), bu arenanın kritik işlevini kurtarmak ve demokrasiyi kurumsallaştırmak için yeni bir kamusal alan biçimi gerektiğine işaret etmektedir. Fraser (1990)'a göre yeterli bir kamusal alan kavrayışı, sosyal eşitsizliğin sadece parantez içine ele alınmasını değil, ortadan kaldırılmasını gerektirmektedir. Fraser'a göre bunun önkoşulu, sosyo-ekonomik bir eşitliktir. Fraser kamusal alanın devlete ait olmadığını söyler. Ona göre bu alanda hükümetlerin dişında söylemsel kamuoyunun oluşumu gayri resmi şekilde işlemekte ve devlete karşı bir denge unsuru oluşturmaktadır. Burada toplumsal eşitsizlikler ortadan kalkmıştır (Köselerli, 2017, s.54-55).

Arendt (1998), kamusal terimini açıklarken birbiri ile yakından ilişkili fakat tamamen aynı olmayan iki fenomene işaret etmektedir. Birincisi, halka açık olarak meydana gelen her şeyin herkes tarafından görülebilmesi ve duyulabilmesine imkân tanıyan bir teşhirin olmasıdır. İkincisi ise kamunun herkes için ortak bir dünyayı ifade etmesidir. Kamusal alan, ortak dünya olarak bizi bir araya getirir. Arendt'in bu yaklaşımı, bir izafet çerçevesini ve kamusal alanı oluşturan kamuoyuna erişimi olanaklı kılan ortam ve/veya araçlara işaret eder. Kahraman (2019), Arendt'in eylem ve söylem yolu ile üretilen kamusallıklarının başka insanların kamusallıklarının oluşturduğu bir ağ ile çevrili olduğunu ve bu ağ ile sürekli etkileşim halinde olduğunu aktarır.

Tarde kamusal alan için, muhakeme ve mantık süzgeçlerinden geçirilmiş akılcı kanaatlere sahip bir kamunun ortaya çıktığı bir model tanımlamaktadır. Ona göre kahvehane, kulüp ve salonlarda gerçekleşen politik tartışma ve müzakereleri ateşleyen gazetelerin hızla yaygınlaşmasıyla eş zamanlı olarak kamusal alan oluşmuştur. Tarde' in 
tanımladığ1 kamusal alan modeli etkileşim halindeki dört unsurdan oluşmaktadır. Bu unsurlardan ilkini, sıklıkla hükümetin çalışmaları hakkında kamuya bilgi aktaran, kamusal tartışma ve müzakereler için gündem yaratan basın oluşturmaktadır. İkincisi kahvehaneler, kulüpler ve salonlarda bir araya gelen kişiler arasında gerçekleşen sohbetlerdir. Bu mekanlarda gerçekleşen sohbetlerde dile getirilen kanaatlerin, zihinsel süzgeçlerden geçirilip berraklaşması, bir veya iki genel kanaate dönüştürülerek kristalize olması ile oluşan kamuoyu üçüncü unsuru oluşturmaktadır. Ve son unsur, kamuoyunun bireysel veya kolektif eylemlere yol açmasıdır (Çebi, 2013, s.10-11).

Belirtilen üç farklı kamusal alan yaklaşımının ortak noktası ortak bir mekânın paylaşımı, bu mekanlara bir kısıtlama olmaksızın erişim, kanaatlerin herkes tarafından fark edilir şekilde özgürce ifade edilmesi ve ortak faydadır.

\section{Medya ve Kamusal Alan}

Kamusal alan tartışmalarında medya merkezi bir konumdadır. Böyle olmasının sebebi, kitle iletişim araçlarının kamusal iletişimi mümkün kılması ve kamusal bilgi ile anlam ufkunun kamuoyunun üretiminde artan bir etkiye sahip olmasıdır (Özbek, 2004b, s.444). Kamusal alan olgusunu medya merkezli kavramlaştıran araştırmacılara göre basım-yayın araçları, eylem ve fikirlerin şekillenmesini ve küresel ölçekte taşınmasını mümkün kılmakta; yeni kamusallık biçimlerini şekillendirmektedir.

Kamusal alanın şekillenmesinde medyanın etkin bir rolü olduğunu belirten yaklaşımlara göre kamusal alan, "toplum üyelerinin, ortak ilgi alanlarını tartışmak ve böylece ortak bir akıl oluşturabilmek için çeşitli medyalar aracılığıyla ya da yüz yüze olacak şekilde buluştuğu kabul edilen ortak bir alan" olarak tanımlamaktadır (Taylor,1992, s.220). Curran'a göre medya, çeşitli çıar gruplarının kamusal alana katılımlarını kolaylaştırarak kamusal tartışmalara katkı sağlamalarına ve kamu politikalarını yönlendirmelerine imkân vermeli; kamusal denetime ve kamuoyu ilgisine açılmalıdır. Piyasa süreçleri ile kolektivist kamu hizmeti yayıncılığının birleşmesiyle oluşacak yeni medya modelleri, farklı sınıf ve grupların eşit şekilde kamusal diyaloğa katılmasına imkân sunacak; yurttaşların kendi çıkarlarını tanımlayabilecekleri bir ortam sağlayacaktır. 
Böylece medya, hükümetlerden ve piyasalardan bağımsız yeni bir kamusal alan olarak yeniden oluşturulabilecektir (Avc1, 2010, s.32-34).

İşleyen bir kamusal alan, toplumda bilginin, fikirlerin, tartışmaların dolaşımına ve siyasi iradenin (yani kamuoyu) oluşumuna izin veren iletişimsel alanların bir kümesidir. Kitle iletişim araçlarının ve yeni interaktif medyanın öne çıktığı bu alanlar, vatandaşlar ile toplumun iktidar sahipleri arasındaki iletişimsel bağları da kolaylaştırmaya hizmet etmektedir (Dahlgren, 2005, s.148).

Medyanın gelişmesi ve bu gelişmenin imkân verdiği erişimin yaygınlaşması, geleneksel bir aradalık kamusallığından farklı; eylem ve olayların ortak bir mekânın paylaşılmasını gerektirmediği yeni kamusallık biçimleri sağlamaktadır. Eylemler ve olaylar çeşitli araçlar yardımıyla kaydedilerek kamusallaştırılabilir ve o olaylara görgü tanıklı̆̆ı yapmamış olan kişilere iletilebilir; böylelikle bağımsız, "dolayımlı bir kamusallık" kazanabilirler. Yaygınlaşan yeni iletişim medyasıyla birlikte gelişen yeni kamusallık biçimleri, geleneksel kamusallığı tamamlamakta, genişletmekte ve yerinden etmeye başlamaktadır (Thompson, 2019, s.158). Bu yeni tür dolayımlı kamusallık, şeffaflığa, erişilebilirliğe ve görülebilir kılmaya dair bir kamusallıktır; bireyler artık ortak meseleleri tartışmak için, ortak bir mekânda bulunmaya ihtiyaç duymamaktadırlar (Thompson, 2019, s.288). Böylece kamusallık ve fiziki birliktelik arasındaki bağ zayıflamıştır.

\section{Yeni Kamusal Alan}

Çoğu araştırmacıya göre, 21. yüzyılda kullanım alanı genişleyen yeni iletişim teknolojileri, internet ve yeni medyanın sunduğu olanaklar yeni kamusal alanlar yaratmıştır. Bu yenilikçi ve teknoloji belirlenimci bakış açısına göre, sanal mekânda var olan ortamlar fikir ve düşüncelerin paylaşılmasına, tartışmaların başlatılmasına ve sürdürülmesine olanak tanımakta, çeşitli düzeyde toplumsal örgütlenmeler için mekândan bağımsız yeni ortamlar sunmaktadır. Köselerli (2017), internet ortamında bir kampanyaya katılmanın, web sitelerinde yer alan içeriklere yorum yapmanın ve Twitter'da içerik paylaşmanın kamusal söylemi inşa eden etkinlikler olduğunu belirtmekte ve etkileşimsel yeni medya ortamının 
sosyo-politik yaşamın yeni kamusal alanları şeklinde nitelendirildiğini ifade etmektedir.

Castells'in bilgi ve iletişim teknolojilerinin süratli gelişimine paralel olarak ortaya çıkmış olan "Ağ Toplumu" kavramı da kamusal alan tartışmalarına yeni bir boyut kazandırmıştır (Çalışkan, 2014, s.41). Castells (2008), endüstriyel toplumda medyanın, kamusal alanın ana bileşeni haline geldiğini söylemektedir. Dijital çağda bu hem kitle iletişim araçlarının hem de internet ve kablosuz iletişim ağlarının çeşitliliğini içermektedir. Kamusal alan, yalnızca medya veya kamusal etkileşimin sosyo-mekânsal siteleri değildir; aynı zamanda kamusal tartışmaları besleyen fikirlerin ve projelerin kültürel/bilgi deposudur.

Castells (2008)'e göre çağdaş küresel kamusal alan, büyük ölçüde küresel/yerel medya sistemine bağlıdır. Bu medya sistemi, aralarında internet ve yatay iletişim ağlarının artık belirleyici bir rol oynadığı televizyon, radyo ve yazılı basının yanı sıra çeşitli multimedya ve iletişim sistemlerini içerir. Bölgesel olarak birbirine bağlı toplumların ulusal kurumları etrafında demirlenmiş bir kamusal alandan, medya sistemi etrafında oluşturulan bir kamusal alana geçiş vardır. Küresel medya ve internet ağları aracılığıyla dünya kamuoyunun gücünü kullanmak, hükümete dayalı uluslararası kurumlar ve küresel sivil toplum arasında verimli, sinerjik bir bağlantı oluşturarak küresel ölçekte siyasi katılımı genişletmenin en etkili şeklidir. Bu çok modlu iletişim alanı, yeni küresel kamusal alanı oluşturmaktadır.

Kamusal alan yerine kamusal mekân kavramını kullanan Van Dijk (2016), belirli bir topluluk ya da ulusun diğerleriyle tanışmak ve bütünleşmek için artık bir bölgeye bağlı olmadıklarını, kamusal mekânların sokak, kahve ve pazarlarla sınırlı kalmadığını, artık hem çevrimiçi hem de çevrimdışı kamusal mekânların olduğunu söylemektedir. İnsanlar artık eski medyayı, uydu yayıncılığı ve telefonu, internet gibi yeni iletişim araçlarını sanal ve hayali topluluklar oluşturmak ve kamusal mekânlarını kurmak için kullanabilmektedirler. Modern toplumda kamusal alanın hayali sınırları artık silikleşmiştir. Kamusal alan, internet, Twitter mesajlarından oluşan hiper bağlantı yapısı gibi farklı ebatlarda ve birbirine bağlı kamusal mekânlardan oluşan karmaşık bir mozaiğe dönüşecektir. Sosyal medyada sosyal, siyasi ve kültürel tartışmaların oluşu, şimdiden farklılaşmış kamusal mekâna yeni mekânlar eklemektedir. 
Fuchs (2020), sosyal medya çağında, toplumda çok sayıda insana ulaşan büyük kamusal alanlara duyulan ihtiyacı dile getirmektedir. Ona göre sosyal medya, daha büyük bir kamuoyu oluşturarak sürdürebilir. Fuchs (2020), sosyal medyanın biliş, iletişim ve iş birliği olmak üzere üç sosyallik biçiminin bütünleşik bir sosyallikte yakınsamasını sağladığını ifade etmektedir. Buna örnek olarak Facebook'ta bir bireyin bilişsel seviyede bir video yaratması, başkalarının yorumlayabilmesi için onu paylaşması ve başkalarının içeriğe müdahale edebilmesinin mümkün kılınmasını gösterir. Ona göre teknoloji, bu üç etkinliğin tümünü bir arada birleştirebilmektedir. Facebook ise, bir sosyal alan içerisinde sosyalliğin bir aşamasından diğerine geçişi teşvik etme potansiyeline sahiptir. Buna göre, bilişsel seviyede bir etkinliğin gerçekleşebilmesi, etkileşim içinde sunulabilmesi somut bir mekâna bağlı kalmayı yok saymaktadır.

Trenz (2009) dijital medyanın, siyasi kamusal alanın sınırlarını nasıl yeniden tanımladığını analiz etmektedir. Ona göre dijital medya ve internet, ulusal kamusal alanın temsil edilebilirliğinin yerini almada açı bir şekilde sınırsız siyasi iletişim sağlamamaktadır fakat ulusal kamusal alanı yeniden üretmeye devam etmektedir. Trenz (2009), dijital kamusal alanın ulusal kamusal alan temsilciliğinin yerini aldığı, yeni bir özgürleştirici potansiyeli ortaya çıkardığ 1 ve siyasi iletişimin katılımcı ve etkileşimli unsurlarını güçlendirdiği şeklindeki ana varsayıma karşı çıkmaktadır. Bunun nedeni, internetin kamusallık ve temsil iddialarını çoğaltmakla birlikte kamusal rezonans alanlarını en aza indirmesidir. Pek çok bilgi sağlayıcının rolü, bu nedenle, girdi sağlamaktan kamusal muhakemeye ve tartışmalardan kendi kendini temsil etmeye, kendi kendini tanıtmaya ve imaj politikasına kaymaktadır.

Yeni medyanın herkese eşit erişim ve katılım sağlayan demokratik bir kamusal alan sunduğu yönündeki liberal savunuyu eleştiren Sparks, yeni medya aracılığıyla enformasyona erişimin arttığını kabul etmekte fakat toplumun her kesiminin teknoloji üretimini gerçekleştiremediğini belirtmektedir. Çünkü teknoloji üretimi, sermaye sahibi devlet veya devlet dışı aktörlere ihtiyaç duymaktadır. Bu nedenle ona göre yeni medya, seçkinler arasında iletişimi sağlayan bir araçtır (Köselerli, 2017, s.57-58).

\section{Kamusal Alan ve İnternet}


Castells (2008), internet ve kablosuz iletişimin hem bir düzenleme hem de tartışma, diyalog ve toplu karar verme için bir araç sağladığını ifade etmektedir. Sparks'a göre devletin uyguladığı sansür, piyasa sahipliği gibi yapısal etkenler kamusal alana çeşitli kısıtlılıklar getirmektedir. Sanal ortamda iletişim karşılıklı etkileşime dayanmaktadır ve internet daha katılımcı bir demokrasi biçimlerinin oluşmasına yönelik bir ortam yaratma potansiyeline sahiptir araçtır (Köselerli, 2017, s.57-58).

Dahlgren (2005), tüm yurttaşları, belirli bir dizi iletişimsel ve kültürel geleneklerle tek bir kamusal alana sokma hedefinin, genellikle çoğulculuk ve farklılık gerekçesiyle reddedildiğini ifade etmektedir. Farklı gruplara ve kültürlere mensup yurttaşlar, hatta farklı dillerde konuşanlar katılımı anlamlı bulacakları, bazı noktalarda iç sorunlarını çözebilecekleri ve/veya kolektif bir kimlik geliştirebilecekleri ayrı bir alana ihtiyaç duyabilirler. İnternetin kamusal alana en açık şekilde katkıda bulunduğu yer burasıdır.

İnternet tabanlı kamusal alanlar, hükümet temsilcilerinin vatandaşlarla etkileşime girdiği ve devlet idaresi ve hizmetleri hakkında bilgilerin sunulduğu, genellikle yukarıdan aşağı karaktere sahip e-devlet sürümleri; tartışmanın sıklıkla paylaşılan algılara, değerlere ve hedeflere sahip kuruluşlar tarafından çerçevelendirildiği ve siyasi müdahale biçimlerine göre düzenlendiği savunuculuk/aktivist alanı; vatandaşlar arasında görüş alışverişinin ve müzakerelerin yapılabildiği çok çeşitli sivil forumlar; ortak çıkarlar ve/veya kolektif kimliklerle ilgili sosyal ve kültürel konuları yayınlayan alanlar; çevrimiçi olan büyük haber kuruluşlarından (örneğin, gazeteler ve $\mathrm{CNN}$ ) Yahoo! gibi net tabanlı haber kuruluşlarına kadar her şeyi içeren gazetecilik alanları ile haberler, Indymedia ve Mediachannel gibi alternatif haber kuruluşları ve tek kişilik web günlüğü siteleridir. Çevrimiçi gazetecilik sektörünün de internetteki kamusal alanın temel bir unsuru olduğu unutulmamalıdır (Dahlgren, 2005, s.153).

İnternet tabanlı ağlar ve yeni medyanın, katılımcı demokrasiyi güçlendirip kamusal alanları çeşitlendireceği görüşüne şüphe ile yaklaşan araştırmacılar vardır. Bu doğrultuda fikir beyan eden araştırmacıların ağırlıklı dayanağı yeni medyanın ekonomi-politiğinin özerk bir yapıya sahip olup olamayacağı, sansür mekanizmasının bu alandaki işlerliği ve internet ile iletişim teknolojilerine toplumun her kesiminden erişimin mümkün olup olmayacağıdır. 
Sparks (2003)'a göre kamusal alanı geliştirmede web'in potansiyelinden yararlanma yeteneği, yalnızca ticari kısıtlamalardan görece bağımsız olan medya kurumları için mümkündür. Bu kantlara göre internet, kamusal alana yeni bir soluk kazandırmaktan çok uzakta kalacak, sosyal eşitsizliğin gerçekleri, kendini çevrimiçi ortamda daha da güçlü bir şekilde gösterecek gibi görünmektedir. Sonuç, kamusal hayata erişimin genişlemesinden ziyade daralması olacaktır.

İnternetin ortak sorunlar ve çözümler yoluyla kamusallığı tanımlama kapasitesi ile siyasi tartışmaları teşvik etme performansı sınırlı kalmaktadır. İnternetin bir siyasal iletişim alanı olarak kısıtlanmasının ilk nedeni, ulusal kamusal alanın ana bilgi sağlayıcıları olarak geleneksel haber medyasının tekelinin hala kırılmamış olmasıdır. İnternet haberleri, genellikle ana akım basılı ve televizyon haberlerinin "atık bir ürünüdür". Dijital medya, haber üretim kurumları ile dağıtım kanalları arasında yeni bir ayrım yaratmıştır ancak siyasi haberlerin ortaya çıtığı ve halkın yankı bulduğu alanı daha az etkilemektedir (Trenz, 2009, s.12). İkinci nedeni, internetin, ulusal olarak korunan haber pazarlarını açma girişiminde, örneğin telif hakkı kısıtlamaları biçiminde ciddi kısıtlamalarla karşı karşıya olmasıdır. Üçüncü nedeni, ortalama internet kullanıcısı için, dünya çapında ağda gezinirken dilin hala ana engel teşkil etmesidir. Bundan dolayı internet, tüketicilerin politik bilgileri esas olarak ulusal ve genellikle tamamen yerel web sitelerinden aldıkları ulusal nişlere ayrılmaktadır. Ayrıca bloglar, ulusal veya yerel kamusal alanlara sıkı bir şekilde yerleşmiştir ve temelde dışarıdan kullanııılar tarafından erişilememektedir. Amerikan çevrimiçi haber sunucuları ve blogları, çoğu Avrupalı kullanıcı için okunaksızdır. Tartışmalar dar bir şekilde tanımlanmıştır ve esas olarak kendine referanslıdır. Kodları anlayan ve endişelerini paylaşan Amerikalı kullanıcıların belirli bölümleri için yapılmıştır. Blog alanı, bu anlamda ulusal kamusal alanın içine sıkı bir şekilde yerleştirilmiş olup, esas olarak ulusal konulara atıfta bulunarak ve ulusal gazeteciler ve medya ürünleri arasında ağ kurarak, vatandaşlar arasında özel bir iletişim kurmaktadır. Dördüncü nedeni ise medyanın ticari mantığıdır (Gurevitch ve Levy 1990'den akt. Trenz, 1990, s.14).

Papacharissi (2009), araştırmalarında kamusal alanı tanımlayan, ona karşı çıkan ve interneti bir kamusal alan olarak ele alan modelleri incelemekte ve internetin kamusal alan potansiyelini üç eğilim dahilinde 
açıklamaya çalışır. Bunlar bilgiye erişim, karşılıklı iletişim ve çevrimiçi alanın ticarileştirilmesidir. Ona göre internet ve çevresindeki dijital teknolojiler bir kamusal mekân oluştururken, ille de bir kamusal alan sağlamaz. Çevrimiçi medyanın sağladı̆̆ı bilgiye daha fazla erişim, doğrudan siyasi katılımda artışa veya daha fazla sivil katılıma veya siyasi sürece olan güvene yol açmaz (Bimber, 2001ve Kaid, 2002'den akt. Papacharissi, 2009, s.234) Bir kamusal alan olarak internetin avantajlarından, yalnızca ona erişimi olan seçilmiş birkaç kişi faydalanabilir, böylece açık bir kamusal alan yanılsaması barındırır (Sassi, 2005; Pavlik, 1994; Williams, 1994'dan akt. Papacharissi, 2009, s.234). Jankowski ve van Selm (2000) tarafından yürütülen bir araştırma, çevrimiçi tartışmaların elitler tarafından yönetildiğini ve nadiren çevrimdışı etkileşim alanına yayıldığını göstermiştir. Çevrimiçi siyasi müzakere ile ilgili yapılan diğer araştırmalar, internetin toplu kullanımının daha fazla siyasi katılıma imkân verebileceğini, fakat bu durumun güven ve karşllkkllık ile mümkün olabileceğini ortaya çıkarmıştır (Kobayashi, Ikeda ve Miyata, 2006'dan akt. Papacharissi, 2009, s.235). Papacharissi (2009), ticari altyapısını koruması dolayısıyla çevrimiçi dijital teknolojilerin bir kamusal mekân yarattığı, ancak kaçınılmaz olarak bir kamusal alanı etkinleştirmediği sonucuna işaret etmektedir. Şimdiye kadar yapılan araştırmalar bilgiye erişimin, karşılıklı iletişimin ve ticarileştirmenin kamusal mekândan kamusal alana geçişi engelleyen üç temel koşul olduğunu göstermektedir. Yeni bir kamusal mekân, yeni bir kamusal alanla eşanlamlı değildir, çünkü sanal bir mekân tartışmayı basitçe geliştirir; sanal bir alan demokrasiyi geliştirmelidir. Eldeki teknolojiler ortak alan yaratır, ancak "ortak değer" oluşturmazlar.

\section{Yurttaş Gazeteciliği Kavramı}

İletişim ve enformasyon teknolojilerinin gelişimi, toplum fertlerinin doğru, yeterli ve güvenilir enformasyon arayışı aktivitelerini de genişletmektedir. Eski ve yeni medya arasında enformasyon akışının gerçekleştiği "medya yakınsaması", medya üreticileri ve tüketicileri arasındaki ilişkiyi yeniden düzenlemektedir (Liu, Palen, Sutton, Hughes ve Vieweg, 2019, s.68-69). Tüketici konumunda olan bireylerin iletişim araçlarının yaygın şekilde kullanılmasıyla birlikte içerik üretir konuma gelmesi, zamanla ana 
akım medyanın da beslendiği kaynaklar oluşturmaya başlamalarına imkân tanımış ve aralarında bir etkileşimin gelişmesine olanak sağlamıştır.

Yurttaş gazeteciliği, "gerçek mesleği gazetecilik olmayan kişilerin iletişim teknolojileri yardımıyla haber üretim sürecine dahil olmasıdır" (İrvan, 2017). Daha geniş kapsamlı bir ifade ile "ücretli çalışan profesyonel gazeteciler dişında yer alan bireylerin içerik toplama, vizyon oluşturma, haber üretme ve yayınlaması" yurttaş gazeteciliği olarak tanımlanmaktadir (Nip, 2006, s.220).

Güncel olaylara dayalı blog oluşturma, fotoğraf ve video paylaşımı ve güncel olaylar hakkında görgü tanığı yorumları yayınlama gibi uygulamaları kapsayan yurttaş gazeteciliği terimi, kimi zaman vatandaşların katılımı ile diğer kullanıcılar veya profesyonel haber kuruluşları tarafından yayınlanan haber materyallerini yeniden yayınlama, link verme, etiketleme, derecelendirme, değiştirme veya bunlara yorum yapma gibi faaliyetleri kapsayacak şekilde oldukça geniş bir şekilde kullanılabilmektedir (Goode, 2009, s.1288). Tüm bu aktiviteler Terry Flew'ın (2005) yurttaş gazeteciliği için tanımladığı açık yayın, kolektiflik, iş birliği içinde üretim ve içeriğin yaygınlaştırılması unsurlarını içermektedir (akt. Saka, 2012, s.42). Yurttaş gazeteciler, "kameraları ile tanıklık ettiği olayları yakalayan, kendi bölgelerindeki olayları hikâyeleştiren kişilerdir" (Goodle, 2009, s.1289).

Edmund B. Lambeth'e göre yurttaş gazeteciliği aşağıda yer alan birtakım özellikleri taşımaktadır (akt. Uzun, 2006, s.646):

- Neyin haber yapılacağını seçme özgürlüğünü korurken bile yurttaşların hikayelerini ve fikirlerini sistematik biçimde dinlemek,

- Önemli topluluk meseleleriyle ilgili hikayeleri çerçevelemenin alternatif yollarını araştırmak,

- Yurttaşı tartışmaya ve meselelerin kamusal anlayışını oluşturmaya teşvik etmede en çok şansa sahip olan çerçeveleri seçmek,

- Önemli kamusal sorunları haberleştirmede, olası çözümlere ilişkin kamusal bilgiyi ve alternatif eylem yönlerinin hizmet ettiği değerleri geliştirecek bir biçimde inisiyatif almak,

- Kamuyla nasıl daha iyi ve saygın bir iletişim kurulacağı konusuna sürekli ve sistematik olarak dikkat etmek.

Yukarıda belirtilen özelliklerde, yurttaş gazeteciliği pratiğinde olaylar haberleştirilirken kamu yararının gözetilmesi ve ortak bir bilinç 
oluşturma kaygısıyla olgunun kapsamının belirlenmesi gerektiği göze çarpmaktadır. Bu yönüyle yurttaş gazeteciliğinin, ekonomik ve ticari olmaktan ziyade sosyal bir amaçla gerçekleştirildiği söylenebilir. Yurttaş gazetecilerin, seçeceği konularla bireyleri tartışmaya çekme misyonuna değinen Lambeth' in belirttiği bu özellik, kamusal alan kavramının oluşumunun yapıtaşını oluşturan ortak akıl yürütme, çeşitli konuları kamuya açık alanda tartışma özeliklerini hatırlatmaktadır.

Yurttaş gazeteciler, kendi başlarına yararlı haber kaynakları olan veya daha fazla haber kaynağı sunabilen fikir liderleri olma eğilimindedir. Gazetenin çevrimiçi forumlarındaki tartışmalara veya canlı sohbetlere katılmaya davet edilebilirler. İlgili vatandaşlarla bağlantı kurmak, toplumla bağlantı kurmaya yönelik stratejik bir adımdır (Nip, 2006, s.230).

Kperogi (2011), web tabanlı yurttaş medyasının kuvvetli bolluğunun, müzakere alanının dinamik genişleme çağını başlatma potansiyeline sahip olduğunu ve hatta söylemsel alanın geleneksel medyanın boğucu egemenliğine karşı bir denge sağladığını belirtmektedir. Ona göre gazetecilik ve okuyucu katkılarının üstünlügü üzerine inşa edilen haber yayınları, yerleşik haber sağlayıcılara alternatifler sunmaya başlamaktadır ve çevrimiçi yurttaş medyası ana akım medya uygulamalarının kültürüne ve geleneklerine dahil edilmektedir.

Bruns ve Atton gibi akademisyenler, yurttaş gazeteciliğinin kendilerini ve topluluklarını güçlendirdiğini ifade etmişlerdir. Böyle bir gazetecilik kavramı, profesyonel anlamda bir gazeteciye ihtiyaç duymamaktadır (Sonwalkar, 2019, s.108). Kapsamlı bir yeteneğe ya da uzmanlığa sahip olmayı gerektirmeyen yurttaş gazeteciliği, uygulayıcı kitlesini sınırsız ölçüde genişletebilmekte ve sınırsız sayıda konuyu içerik olarak sunabilmektedir. Katılımın geniş olduğu bu pratik ile bireyler ortak bir problem etrafında geniş kapsamlı içerik üretebilmekte, toplumda ses getirebilmektedir.

Kısa bir sürede hızlı bir gelişme gösteren yurttaş gazeteciliği, tarihsel öncülleriyle birlikte kültürel sarmalını, sivil toplum politikalarını ve organizasyonel yapılarını ifade etmede büyük başarı kazanmıştır. İnternet sunucuları ağına bağlanmayı ve yüklemeyi kolaylaştıran düşük maliyetli, güvenli iletişim teknolojileri, sosyal ilişkilerin kurulmasında aracı bir konumdadır. Küresel ölçüde farklı siyasi rejimler altında uygulanan yurttaş 
gazeteciliği, ana akım medyanın her noktasında varlığını ortaya koymaktadir (Cottle, 2019, s.11 -12).

Medya, iletişim yeteneğini sergilerken kamuyu yönlendirebilmektedir. Bununla birlikte var olan esas tehditlerin yapısını gizleyebilmekte ve değişim yaratmaya çalışan sesleri sıradanlaştırabilmektedir. Örneğin çeşitli küresel krizlerde oluşan kayıplar ve tükenişin boyutu, medya görünürlüğü olmadığından dünya medyasında küresel kriz olarak işlenmeyebilir ve yeterince tepki çekmeyebilir (Cottle, 2019, s.10). Çoğunlukla kamu çıkarlarını savunan yurttaş gazeteciliği, siyasi iktidarın medyaya taşınmasını istemeyeceği ve gündemin kontrol altında tutulduğu toplumlarda, halkın sesini duyuran bir oluşumdur ve çoğu durumda iktidar için korku unsuru oluşturmaktadır. Bu durum, özellikle basın özgürlüğünün göz ardı edilebildiği ülkelerde önem taşımaktadır. Yurttaş gazeteciliği pratikleri de genellikle toplumların köklü kurumlarını ve güç ilişkilerini sorgulayan siyasi aktivitelerle ilişkilendirilmiştir. Dünya çapında baskıcı hükümetler blog içeriklerine katı sınırlamalar getirmeye çalışmışlar ve yurttaşlara sansür ya da kısıtlama olmaksızın kendilerini ifade etme hakkını tanımamışlardır (Allen ve Thorsen, 2019, s.20-28). Çoğu ülkede yurttaş gazeteciliği, bu koşullar altında varlığını korumaya çalışmaktadır.

Grupların çıkarlarını ve ideallerini yükseltmek için faal biçimde seferber olmaları eğilimi, siyasal etkinlik ve katılım kavramlarıyla beslenen bir dünyanın özelliğidir. Toplumsal hareketler, belirli bir siyasi düzen içinde bölündüklerinde veya siyasi otorite tarafından etkili bir şekilde baskı altında tutulduklarında, grup kaynaklarını bir araya getirme aracı olurlar. Devrimci hareketler, hükümetlerin baskı kullanarak gücünü sürdürmeye çalışması durumunda, çoklu egemenlik ortamında ivme kazanmaya eğilimli olmaktadır. Bu sıklıkla, nüfusun çoğunluğunu oluşturan bir kesimin önceden devleti karşılaması yönünde uyardığ1 ihtiyaçları öngörme konusunda, hükümetin ani bir isteksizliğine ya da yetersizliğine bağlı olmaktadır (Giddens, 2001, s.85-86). Yurttaş gazeteciliği, bireylerin mevcut çözümsüzlük ve yabancılaşma duygularının üstesinden gelmelerini sağlayabilmek adına onları katılıma teşvik edecek imkanlar yaratmayı amaçlamaktadır. Bu da haberin oluşum sürecinde bireylere söz hakkı tanıyarak, bir kamusal tartışma ortamı yaratılmasıyla gerçekleştirilmeye çalışılmaktadır (Uzun, 2006, s.646). Böylelikle yurttaş 
gazeteciliği, ortak çıkarlar doğrultusunda, bir çözüm arayışı misyonuyla bir aradalığı teşvik etmektedir.

\section{Yurttaş Gazeteciliğinin Yeni Kamusal Alan Olarak Tartışılması}

Yurttaş medya kanalları, sıradan insanların haber toplamasına ve paylaşmasına imkân vermektedir. Singh (2008)'in gözlemlerine göre bireylerin video kliplerle haber içeriği yollamaya başlaması ile birlikte televizyon haberlerinde değişimler yaşanmış; teknolojik imkanlar sayesinde doğası gereği daha demokratik olan kamusal alan oluşmuştur. Sıradan insanlar çoğu durumda kameralarını yolsuzluk ve diğer anti-sosyal aktivitelere karşı bir güç olarak kullanmaya başlamışlardır (Sonwalkar, 2019, s.111). Yurttaş gazeteciliği, bireylerin ana akım ve alternatif haber içeriklerine katkıda bulunma yeteneği sayesinde oluşan kamusal alanın zenginleşmesini sağlamakta ve demokrasilerin vazgeçilmesi olan sorumlu ve bilinçli yurttaşların fikirlerini daha geniş olarak ifade etmesine olanak tanımaktadır (Sonwalkar, 2019, s.106). Habermas, yurttaş gazeteciliğini, "sanayileşme ve kentleşme ile birlikte artan okuryazarlık düzeyi ve popüler basının büyümesi, yurttaşların kültür ve siyaset tartışmacısı konumundan medya tüketicisine doğru gitmesiyle tehlikeye girmiş olan kamusal alanın yeniden tespiti ve kamuya etkin olabilme imkânı sunan toplumsal uzlaşmanın temsilcisi olacak bir yöntem" olarak değerlendirmektedir (Yıldız'dan aktaran Askeroğlu ve Karakulakoğlu, 2019, s.517).

Stromer ve Galley'e göre internet, yüz yüze ortamlarında siyaset hakkında konuşurken çok fazla tabu ve çok fazla rahatsızlık olduğunu fark eden birçok insana katılım fırsatı sunmaktadır (akt. Dahlgren, 2005, s.159). Bu bağlamda, internet ve çevrimiçi medya sanal bir alanı barındırabilir veya kamusal alanı yeniden canlandırabilir (Papacharissi, 2008, s.234). Trenz (2009) de benzer şekilde etkileşimsiz modern bir iletişim durumundan bahseder. Ona göre bu durum, toplumun temsili düzeninin değişmesiyle mümkün olur. Böylece kamusal alan, aktif katılımın neredeyse hiç olmadığı ve etkileşimin esas olarak sanal kaldığ bağllık alanı olarak oluşturulur. Böyle bir kamusal alan, etkileşim yoluyla (yani katılım yoluyla) değil, esas olarak paylaşılan anlam ve söylem yolu- 
yla (yani temsil yoluyla) "bağlllık" oluşturur. Sonwalkar (2019), Hindistan'da internet erişimi ile birlikte yaşanan gelişmelerin kamusal alana görünürlük getirdiğini, haber medyası ile birlikte gelişmekte olan yurttaş gazeteciliğinin, fazla ortak noktası bulunmayan insanlar, bölgeler ve kültürler arasında entegrasyonu artırdığını belirtmektedir. Meikle (2016) medyanın, internet tabanlı ağ oluşturmuş iletişim platformları seti tanımladığını ve kendi kullanıcıları tarafından oluşturulan bir veri tabanını kullandığını, dolayısıyla kamusal ile kişisel iletişimin yakınsamasını mümkün kıldığını belirtmektedir. Meikle'a göre bu tanım diğerleri ile birlikte Facebook ve Twitter, Pinterest ve Instagram, Reddit ve Tumblr, Blogger ve YouTube'u da içermektedir (Fuchs, 2020, s.63). Yurttaş gazeteciliğinin de konumlandığı bu alanlar, yüzeysel bir çıkarımla onun yeni kamusal alanda varlık gösterdiği anlamını taşımaktadır. Fakat bu yapısal temellenişinin ona kamusal alan niteliği kazandırıp kazandırmadığı, daha derinlikli bir tartışmayı gerektirmektedir.

Friedland, Hove ve Rojas (2006) geleneksel medyada hâkim görüşlerin dolaşıma girdiğini, yeni medyada ise alternatif söylemlerin görünürlüğünün arttığını ifade etmektedirler. Yazarlara göre geleneksel medyanın gündem belirleme gücü aşınırken yeni medya bu rolü üstlenmiştir. Bireyler, ağlardan oluşan bu yeni kamusal alanda daha fazla politik etkinliğe ve kamu söylemine katılabilmektedirler. Yeni kamusal alanda bireyler pasif bir enformasyon alıcısı ve dolayımlayıcısı değil, aynı zamanda hem bir konuşmacı hem bir dinleyicidir; kendi kendine enformasyon toplayabilmekte, paylaşabilmekte ve örgütleyebilmektedirler (akt. Köselerli, 2017, s.55). Katılımla geliştirilen kimlikler aracılığıyla insanlar, vatandaş olmanın ve siyaset yapmanın yeni yollarını keşfetmektedir (Dahlgren, 2005, s.159). Yurttaş gazeteciliği gündemi belirleme, politik katılımı sağlama ve enformasyon üretip paylaşma pratiği geliştirmesi itibariyle haber üretim uygulamaları arasındadır. Bu bakımdan yukarıda yer alan görüş çerçevesinde yurttaş gazeteciliği, yeni kamusal alanın bir dinamiğini oluşturur gibi görünmektedir.

Yurttaş gazeteciliği çoğunlukla internete bağlıdır. Çevrimiçi platformu sürdürebilme becerisini ve tasarım bilmeyi gerekli kılmaktadır. Yurttaş gazeteciliği yapanlar, sosyal ağlara içerik yükleme, anlık mesajlaşma üzerinden kullanıcılar ile haberleşme konularına hâkim olmalıdır (Bruns, 
Wilson ve Saunders, 2019, s.269). Benzer şekilde yurttaş gazeteciliği pratiklerine erişecek bireylerin de teknolojik alt yapıya ve bunu kullanma becerisine sahip olması gerekmektedir. Castells (2000), internet bir yana elektriğe erişimin dahi olmadığ 1 ülkelerde yurttaş gazeteciliği pratiğinin sadece akademik bir tartışma alanında kalacağını öngörmektedir (akt. Allan ve Thorsen, 2019, s.21). Bu durumda yurttaş gazeteciliğinin erişimi, katılımı ve kapsayıcılığı sınırlıdır. Dolayısıyla kamusal alan olma niteliğini gölgeleyen bir engel ile karşı karşıyadır.

Yurttaş gazeteciliği, kamu çıkarlarıyla aynı doğrultudadır. Basın özgürlügünün ciddiye alınmadığı ülkelerde bu durum daha fazla öne çıkmaktadır. Bu ülkelerdeki baskıcı hükümetler, bloglara katı sınırlar koymaya çalışmışlar ve yurttaş gazeteciler şöyle dursun, henüz yurttaşlarına dahi özgürce kendini ifade etme hakkı tanımamışlardır (Allan ve Thorsen, 2019, s.20). Böyle bir ortamda uygulanmaya çalışılacak yurttaş gazeteciliğinin, kamusal alanın en temel varsayımlarından biri olan siyasi tartışmaların kapsayıcılığını ve geçerliliğini sağlayabileceği sorunlu görünmektedir. Yurttaş gazeteciliği baskıcı rejimlerden ve sansürden uzaklaşabildiği ölçüde kamusal bir tartışma alanı oluşturabilecektir.

Kamusal alanda tartışmaların bağımsız ve öznel olarak yürütülebilmesi, ekonomi-politiğinin özgür olmasına bağlıdır. Uzun (2006)'a göre yurttaş gazeteciliği savunucuları, bu gazetecilik pratiği ile kamusal alanın canlandırılıp geliştirilmesi arasında bir bağlantı kurarken, medyanın ekonomik yapısına ilişkin ciddi bir argüman sunamamaktadırlar. Habermas (2018)'a göre ticari çıkarlar, kapitalist bir ekonomi ve ana akım medya içeriği, kamusal alanı sömürgeleştirmiş ve uzlaşmacı rasyonel ve demokratik kamusal söylemi yok etmiştir. Piyasa mantığı, ortaya çıan yasal çerçeveler ve siyasi kısıtlamalara yönelik ivme ile birlikte kitle iletişim araçları, oldukça tanıdık olan yollarla sivil amaçlara yönelik temsilin kapsamını ve biçimlerini kısıtlamaya hizmet etmekte ve uygun bir sivil iletişim alanı olma potansiyelini azaltmaktadır (Lessig, 1999, 2001'den akt. Dahlgren, 2005, s.151). Buna ek olarak Yahoo'nun 2005'te Flickr'ı (yurttaş fotoğraf gazeteciliğinde birçok ilginç gelişmeyi barındıran fotoğraf paylaşım sitesi) satın alması, Google'ın 2003'te Blogger.com'u ve 2006'da YouTube'u satın alması ve MSNBC'nin 2007'de Newsvine'ı satın alması, yurttaş gazeteciliğinin ekonomi politiğinin bağımsızlığına zarar vermektedir (Goode, 2009, s.1289). Yurttaş gazeteciliği, gönüllü katılımcılığ1 
esas alan ve kâr amacı gütmeyen bir oluşum olarak yeşermektedir. Ticari bir amaç, içeriklerin bağımsızlığına, tarafsızlığına ket vuracaktır. Böyle bir hedefle oluşturulmuş yurttaş gazeteciliği platformlarının toplumdaki tüm sesleri temsil etmesi kısıtlı kalacağından, yeni bir kamusal alan olarak sorgulanması da geçerliliğini yitirecektir.

Saka (2012, s.41), yeni medya uygulamalarının gazetecilikle birleşmesinin geleneksel gazetecilik otoritesini sarsmakla birlikte, yurttaşlarla gazeteciler arasında ortaya çıkan daha diyalojik bir üretim sürecinin, kamusal alanı ayakta tutan yapılardan biri olmaktan çıkmış olan gazeteciliği yeniden sürece katabileceğini ifade etmektedir. Bloglar, toplumsal anlatı yaratmaya katkıda bulunmakta ve kolektif anlatı üretmesi dolayısıyla demokratik olarak kendini ifade etme ve ağ kurma faaliyetlerini zenginleştirmektedirler (Law- son-Borders ve Kirk, 2005; Kahn ve Kellner, 2004'den aktaran Saka, 2012, s.41). İran'daki bloglar, ana akım medya platformlarınca görmezden gelinen ticaret birliklerini, kadınların sahip olduğu zor şartları ve radikal öğrenci gruplarını göstermek için bir alan yaratmakta; yenilikçi ve alternatif yurttaşlık ve gazetecilik ifadeleri ile birlikte siyasi şartlara tepki olarak bir canlanma örneği sergilemektedirler (Khiabany ve Sreberny, 2019, s.163-175). Sosyal medyayı, enformasyonun sosyal bağlantılar arasında bir tartışma veya topluluk oluşturmak için bir ortam olarak tanımlayan Standage (2013), blogların yeni broşürler; mikrobloglar ve çevrimiçi sosyal ağların yeni kahvehaneler olduğunu söylemektedir (akt. Fuchs, 2018, s.62). Fuchs (2020) blogların, kültürel katılımda bariyerleri düşüren, bakış açılarını genişleten, herkesin sesini duyurabildiği aracılar olduğu görüşünü eleştirmektedir. Ona göre birçok blog, kamusal alandaki görünürlükten yoksundur ve siyasi bloglar, ticari büyük haber odaklarına ait web sitelerinin okuyucularına neredeyse hiç ulaşamamaktadır.

Fuchs (2020)'a göre internetteki mikro kamular tek başına yeterli değildir ve bu kamular, kamusal alanı bölmekle tehdit etmektedir. Dolayısıyla sosyal bağlantıları güçlendiren küçük kamusal iletişim alanları önemli olsa da sosyal medya çağında, toplumda çok sayıda insana ulaşan büyük aracılı kamusal alanlara ihtiyaç vardır. Fuchs'un önerisi, yurttaşları içerik üretimine dahil etmek için kullanıcı tarafından oluşturulan içerik fikrinin daha ciddiye alınmasıdır. Büyük şirketlerin sosyal 
medyayı sömürgeleştirdiğine vurgu yapan Fuchs (2020), şirketleşmemiş alternatif bir internete ihtiyaç olduğunun da altını çizmektedir.

\section{Sonuç}

Toplumlar, her çağa özgü dönüşüm ve devinim içindedirler. Geçmişten gelen her birikim geleceğe yön vermekte; şimdi ve gelecek de bu birikimler üzerinde temellenip gelişerek kendi yeniliklerini oluşturmaktadır. 21. yüzyılın yaşam evresinde dahil ettiği en büyük değişimlerden biri teknoloji kullanımının büyük oranda günlük yaşamın bir parçası haline gelmesi ve toplumun ağlaşarak farklı alanlarda yeni pratiklere sahip olmasıdır. Bu dönüşüm, kamusal alan olgusunu da yeni boyutlarda yeni tartışmalara açmıştır. İlgili tartışmalar arasında internet ve yeni medyanın yeni kamusal alanlar oluşturup oluşturmadığı sorgusu vardır.

Yukarıda yer alan olgudan hareketle bu çalışmada, katılımcılığa olanak sağlayan yapısı ile yurttaş gazeteciliğinin yeni bir kamusal olarak konumlandırılıp konumlandırılamayacağı, çeşitli benzer ve karşıt görüşlere yer verilerek tartışılmıştır. Kamusal alan kavramının geleneksel anlamının açıklanması ile birlikte yeni kamusal alan görüşleri incelenmiş; yurttaş gazeteciliğinin sahip olduğu özellikler itibari ile kamusal alan olarak nitelendirilmesinin belli bazı koşullara bağlı olduğu sonucuna varılmıştır.

Geleneksel anlamda kamusal alanlara katılım özgür iradelidir ve eşitlikçidir. Bu yönden tüm bireylerin erişimine açıktır. Kamusal alanlarda ortak ilgiler ve faydalar konuşulmaktadır. Doğası gereği, kamuyu ilgilendiren her konu, bu alanlarda herkes tarafından görülebilir ve duyulabilir olmalıdır. Fikirler serbest dolaşıma sahiptir ve kanaatler kısıtlama olmaksızın sergilenebilir. İnternet, teknoloji ve medyadaki yeni gelişmelerle birlikte geleneksel anlamdaki kamusal alan genişlemekte ve yerini giderek yeni kamusallığa bırakmaktadır. Çoğunlukla yeni medya araçları ile şekillenen yeni kamusal alanlarda katılım fiili değil temsilidir.

Bununla birlikte yeni kamusal alanlar, sınırsız erişime sahip mekanlar değildir. Bu alanlara katılım ülkelerin teknolojik alt yapı imkanlarına ve bireylerin bu teknolojik imkanları satın alma gücüne bağlı olarak değişiklik göstermektedir ve internetin sunduğu imkanlarla sınırlı kalmaktadır. 
Yurttaş gazeteciliği pratiğinin uygulanabilmesi ve bu uygulamalara erişim imkânı da teknolojik sahiplik ile ilişkilidir.

Yurttaş gazeteciliği, web sayfaları, bloglar ve çeşitli sosyal ağlarda faaliyet göstermektedir. Bu alanlar, tanıdıkları görece sınırlı imkanlar sayesinde yeni kamusal alanlar olarak konumlandırılmaya başlanmıştır. Yurttaş gazeteciliğinin de bu alanlarda içerik oluşturup paylaşıyor olması; ayrıca ele aldığı konular itibariyle de toplumdaki farklı görüşleri barındırıyor olması, onun bir kamusal alan olarak kabul edilebileceğini düşündürmektedir. Fakat bunun koşulları vardır.

Kamusal alanların en önemli özelliklerinden biri, her yöndeki görüşün dile getirilip tartışabileceği alanlar olmasıdır. Bu alanlarda uygulanacak herhangi bir ayrımcılık ya da kısıtlama, kamusal alan potansiyeline gölge düşürmektedir. Yurttaş gazeteciliğinin faaliyette bulunduğu alanlar, yaptırımlardan, yönlendirmelerden ve sansür mekanizmasından muaf olduğu sürece kamusal alan olarak kabul edilebilir.

Piyasa sahipliği mekanizması da yeni kamusal alanlardaki görünürlüğün, ekonomik üstünlüğü ellerinde bulunduran mekanizmaların lehine işlemesine yol açabilmektedir. Böyle bir durumda güçlü olanların sahip olduğu ideolojiler daha yoğun temsil edilirken, daha güçsüz olanların farkındalık yaratması zorlaşmaktadır. Yurttaş gazeteciliği, ancak ekonomik olarak bağımsız, ticari kaygılardan uzak platformlarda konumlandığında kamusal alan niteliği kazanabilecektir.

Kamusal alanlara erişim imkânı sınırlandırılmış olmamalıdır. Aynı şekilde yurttaş gazeteciliği de erişim, görüş bildirme, yorum yapma şeklinde belirtilebilecek çeşitli katılımcılık olgularına açık olmalıdır. Lakin internet bağlantısı ve teknoloji sahipliği katılımcılığı etkilemektedir. Günümüzde çoğu kişinin bu imkanlara sahip olması bu durumu bir etken olmaktan büyük ölçüde çıkarmış olsa da gelişmekte olan ülkelerde hala engel teşkil edebilmektedir.

Yurttaş gazeteciliği 1990'l1 yıllardan bu yana uygulanan bir pratik olsa da bilinirliği halen kısıtlıdır. Ayrıca yurttaş gazeteciliği içeriklerine erişmek ve bu platformlarda paylaşımda bulunmak da belli bir farkındalık ve teknolojik okuryazarlık ile medya okuryazarlığı yeterliliği gerektirmektedir. Bu durum katılımcılığı belli bir düzeye bağlı kılmakta, dolayısıyla kısmen engel teşkil etmektedir. Bu durumda yurttaş gazeteciliğinin kamusal alan niteliğinin kısıtlı olduğu söylenebilir. 
Baskıcı rejimlere ve medyada tekelleşmeye karşı büyük bir umut vaat eden yurttaş gazeteciliğinin yeni bir kamusal alan olma potansiyeli şüphesiz yüksektir. Fakat bunu sağlayabilmesi, ekonomi-politiğinin bağımsız olmasına; baskı, tekelleşme ve sansürden uzak olmasına; katılımcılıkta eşitliğin sağlamasına ve tüm görüşlerin eşit şekilde temsil edilebilmesine bağlıdır. 


\title{
EXTENDED ABSTRACT
}

\section{Citizen Journalism in Terms of Potential for Creating a New Public Sphere}

\author{
Nihal Paşalı Taşoğlu - Sema Çağlayan \\ Kocaeli University
}

With the development of communication and information technologies, societies are experiencing a transition towards a "network society" and individuals are discovering how to move from consumer to producer by using technology. And individuals practice on creating collective perceptions, uniting around various ideas and strengthening the participatory culture in a society which interacts through various communication networks. These developments point to the search for a new public sphere and the concept of citizen journalism, where individuals can feel free and independent of the state and the market economy. The aim of this study is to discuss whether the concept of citizen journalism can be defined as a new public sphere in terms of its characteristics. Within this framework, public sphere approaches and citizen journalism were reviewed first, and then the public sphere character of citizen journalism was discussed in the context of the new public sphere approaches formed around the media, internet and social networks. The method used in the study is literature review.

In the traditional sense, participation in public spheres is egalitari-an and by free will. In this respect, it is available to all individuals. Common interests and benefits are discussed in public spheres. By its very nature, every issue of public concern should be visible and audible by everyone in these spheres. Ideas are free to circulate, and opinions can be expressed without restriction. The breadth and limits of the public sphere available in a society determine how developed the freedoms of thought, expression, discussion, access to information, organization and recognition are, and the inclusiveness of everyone, regardless of the individual (Özbek, 2004a, p.32). With the new devel-opments in the internet, technology and media, public sphere is ex-panding beyond its traditional meaning, grad- 
ually yielding to a new concept of the public. Participation in the new public spheres, which are mostly shaped by the new media tools, is not in action but by representation.

However, new public spheres do not have unlimited access. Participation in these areas depend on the technological infrastructure of the countries and individuals' purchasing power of these technological facilities, and is limited to the possibilities offered by the internet. The practice of citizen journalism and the opportunity to access these practices also depend on technological ownership.

Citizen journalism is practiced in web pages, blogs and various social networks. These areas are now defined as new public spheres by virtue of the relatively limited opportunities they provide. The fact that citizen journalism also generates and shares content in these fields, and that it contains various opinions in the society in terms of the issues that it deals with, suggest that it can be accepted as a public sphere. But there are some conditions.

One of the most important characteristics of public spheres is that they provide a medium for all opinions from all perpectives to be expressed and discussed. Any discrimination or restriction in these areas overshadows the potential of the public sphere. Media where citizen journalism operates can be defined as public spheres, as long as they are free of sanctions, manipulation and censorship mechanisms.

Market ownership mechanism can also cause the visibility in new public spheres to work in favor of the mechanisms that hold economic superiority. In such a situation, while the opinions of the strong are represented intensely, it becomes difficult for the weaker to raise awareness. Citizen journalism can acquire the characteristic of a public sphere only when it is built on economically independent platforms that are free from commercial concerns.

Access to public spheres should not be restricted. Likewise, citizen journalism should be open to various forms of participation, such as access, interpretations, and comments. However, internet connectivity and technology ownership affect participation. Although this is usually not an issue as most people have these opportunities today, it can still pose an obstacle in developing countries. 
Although citizen journalism has been a practice since the 1990s, its recognition is still limited. In addition, accessing citizen journalism content and sharing information on these platforms also requires a certain level of awareness, technological literacy and media literacy. This limits participation to certain level and therefore partially constitutes an obstacle. Therefore, it is feasible to say that the public sphere nature of citizen journalism is limited.

In conclusion, the potential of citizen journalism, which makes a great promise against oppressive regimes and media monopolization, to become a new public sphere is undoubtedly high. But its ability to achieve this potential depends on the independence of its economical policy; its freedom from pressures, monopoly and censorship; ensuring equal opportunities in the participation and representation of all opinions.

\section{Kaynakça / References}

Allan, S. and Thorsen, E. (2019). Yurttaş gazetecilik: küresel perspektifler. (İ. S. Temizalp, Çev.). İstanbul: Epsilon (2009).

Arendt, H. (1998). Human condition. London: The University of Chicago Press.

Askeroğlu, E. D. ve Karakulakoğlu, S. E. (2019). Geleneksel medyadan yeni medyaya geçiş sürecinde değişen gazetecilik yurttaş gazeteciliği: Kuşaklar üzerine bir araştırma. Gümüşhane Üniversitesi Illetişim Fakültesi Elektronik Dergisi, 7(1), 508537.

Atabek, N. (2002). Kamuoyu, medya ve demokrasi. Kurgu Dergisi, 19, 223-238.

Avcl, A. (2010). Medya ve televizyon araştırmalarında kamusal alan tartışmalarına giriş. Marmara Iletişim Dergisi, 17(17), 21-43.

Bruns, A., Wilson, J. and Saunders, B. (2019). Sosyal ağ olarak yurttaş gazetecilik: 2007 Avustralya federal seçimlerini haberleştirmek. S. Allan ve E. Thorsen, (Der.) Yurttaş gazetecilik: küresel perspektifler içinde (s.261-273). (Çev. İ. S. Temizalp). İstanbul: Epsilon.

Castells, M. (2008). The new public sphere: global civil society, communication networks, and global governance. The Annals of the American Academy of Political And Social Science, 616(1), 78-93.

Cottle, S. (2019). Önsöz. S. Allan ve E. Thorsen, (Der.) Yurttaş gazetecilik: Küresel perspektifler içinde (s.9-14). (Çev. İ. S. Temizalp). İstanbul: Epsilon.

Çalıskan, O. (2014). Kamusal alan bağlamında ağ toplumu ve yeni kamusal alan arayışı. Maltepe Üniversitesi Illetişim Fakültesi Dergisi, 1(1), 41-62. 
Çebi, Murat S. (2013). Gabriel Tarde'in izinde medyanın işlev ve etkilerini yeniden gözden geçirmek. Illetişim Kuram ve Araştırma Dergisi, 36, 1-28.

Çelebi, A. (2004). Kamusal alan ve sivil toplum: siyasal bir değerlendirme. M. Özbek, (Der.) Kamusal alan içinde (s.237-284). İstanbul: Hil Yayın.

Dahlgren, P. (2005). The internet, public spheres, and political communication: Dispersion and deliberation. Political Communication, 22(2), 147-162.

Fraser, N. (1990). Rethinking the public sphere: a contribution to the critique of actually existing democracy. Social Text, Theory, Culture, Ideology, 25(26), 56-80.

Fuchs, C. (2020). Sosyal medya: eleştirel bir girişs. (D. Saraçoğlu ve İ. Kalaycı, Çev.). İstanbul: NotaBene Yayınları.

Giddens, A. (2001). Sosyoloji: Eleştirel bir giriş. (Ü. Yıldız, Çev.). Ankara: Phonix Yayınevi.

Goode, L. (2009). Social news, citizen journalism and democracy. New Media \& Society, $11(8), 1287-1305$.

Grunig, J. E. and Repper, F. C. (2005). Stratejik yönetim, kamular ve gündemler. J. E. Grunig, (Der.) Halkla ilişkiler ve iletişim yönetiminde mükemmellikiçinde (s.131172), (Çev. E. Özsayar). İstanbul: Rota.

Habermas, J. (2004). Kamusal alan. M. Özbek, (Der.) Kamusal alan içinde (s.95-102) İstanbul: Hil Yayın.

Habermas, J. (2018). Kamusallı̆̆n yapısal dönüşümü. (T. Bora ve M. Sancar, Çev.). İstanbul: İletişim Yayınları (1962).

İrvan, Süleyman (2017). Yurttaş gazeteciliği nedir, ne değildir? 24.05 .2020 tarihinde https://suleymanirvan.blogspot.com adresinden erişildi.

Kahraman, M. D. (2019). Kamusal alanın dönüşümü ve kentsel mekânın iletişimsel niteliği üzerine düşünmek. Planlama Dergisi, 29(3), 195-201.

Khiabany, G. and Sreberny, A. (2019). İran'ın hikâyesi: Hangi yurttaşlar, hangi gazetecilik? S. Allan ve E. Thorsen, (Der.), Yurttas gazetecilik: küresel perspektifler içinde (ss.163-176), (Çev. İ. S. Temizalp). İstanbul: Epsilon.

Köselerli, B. (2017) Yeni medya ortamının yeni kamusal alan olarak kullanımı üzerine bir değerlendirme. Humanities Science (NWSAHS),12(1), 51-64.

Kperogi, F. A. (2011) Cooperation with the corporation? CNN and the hegemonic cooptation of citizen journalis through İReport.com. New Media \& Society, 13(2), 314-329.

Liu, S. B., Palen, L., Sutton, J., Hughes, A.L. and Vieweg, S. (2019). Kriz olayları sırasında yurttaş foto muhabirliği. S. Allan ve E. Thorsen, (Dek.), Yurttaş gazetecilik: Küresel perspektifler içinde (s.67-90), (Çev. İ. S. Temizalp). İstanbul: Epsilon. 
Nip, J. (2006). Exploring the second phase of publicjournalism. Journalism Studies, 7(2), 212-36.

Odabaş, U. K. (2018). Tarihsel süreçte kamusal alanın yapısal dönüşümü ve Habermas. Atatürk Üniversitesi Sosyal Bilimler Enstitüsü Dergisi, 22(Özel Say1), 20512066.

Özbek, M. (2004a). Giriş: Kamusal alanın sınırları. M. Özbek, (Der.), Kamusal alan içinde (s.19-91). İstanbul: Hil Yayın.

Özbek, M. (2004b). Giriş: Kamusal-özel alan, kültür ve tecrübe. M. Özbek, (Der.) Kamusal alan içinde (s.443-500). İstanbul: Hil Yayın.

Papacharissi, Z. (2009). The virtual sphere 2.0: The internet, the public sphere and beyond. A. Chadwick ve P. Howard (Der.). Routledge handbook of internet politics içinde (s.230-245). London: Routledge.

Saka, E. (2012). Siber medya sonrası kamusal alan ve gazetecilik pratikleri. Folklor Edebiyat Dergisi, 18(72). 35-50.

Sonwalkar, P. (2019). Hindistan'da yurttaş gazetecilik: tanınma politikaları. S. Allan ve E. Thorsen, (Der.), Yurttaş gazetecilik: Küresel perspektifler içinde (s.105-117), (Çev. İ. S. Temizalp). İstanbul: Epsilon.

Sparks, C. (2003). The contribution of online newspapers to the public sphere: A United Kingdom case study. Trends in Communication, 11(2), 111-126.

Taylor, C. (1992). Modernity and the rise of public sphere. The Tanner Lectures on Human Values, February, , 205-260.

Thompson, J., B. (2019). Medya ve modernite. (S. Öztürk, Çev.). İstanbul: Kırmızı Yayınlar.

Trenz, H. (2009). Digital media and the return of the representative public sphere. Working Paper, 6, 1-21.

Uzun, R. (2006). Gazetecilikte yeni bir yönelim: Yurttaş gazeteciliği. Selçuk Üniversitesi Sosyal Bilimler Enstitüsü Dergisi, 2006(16), 633-656.

Van Dijk, J. (2016). A $\breve{g}$ toplumu. (Ö. Sakin, Çev.). İstanbul: Epsilon Yayınevi (2012).

\section{Kaynakça Bilgisi/Citation Information}

Paşalı Taşoğlu, N. ve Çağlayan, S. (2021). Yeni kamusal alan oluşturma potansiyeli bakımından yurttaş gazeteciliği. OPUS- Uluslararası Toplum Araştırmaları Dergisi, 18(42), 6025-6053. DOI: 10.26466/opus.893723. 